\title{
Flow in VR: A Study on the Relationships Between Preconditions, Experience and Continued Use
}

\author{
Lobna Hassan \\ Gamification Group \\ University of Turku \\ lobna.hassan@tuni.fi
}

\author{
Henrietta Jylhä \\ Gamification Group \\ Tampere University \\ henrietta.jylha@tuni.fi
}

\author{
Max Sjöblom \\ Gamification Group \\ Tampere University \\ max.sjoblom@tuni.fi
}

\author{
Juho Hamari \\ Gamification Group \\ Tampere University \\ juho.hamari@tuni.fi
}

\begin{abstract}
Flow is characterized as an autotelic experience where action and awareness merge, there is high concentration on task and little attention is paid to time or self. It is believed that VR has a powerful affordance for inducing the flow state, as VR is, at least anecdotally, a technology that transports users to immersive realities, which can facilitate flow. However, VR imposes usability challenges that may inhibit flow. This research investigates flow in VR and its characteristics, determinants and outcomes through a survey $(n=681)$ and Structural Equation Modeling (SEM). The results indicate that flow in VR is positively association with intentions to continue VR use and longer VR sessions.
\end{abstract}

\section{Introduction}

Being perceptually transported to different realities has been a pervasive interest of humankind. Beyond mind-altering substances, technology has been considered to afford possibilities for immersion and transcendence. For example, the camera was believed to suck our soul, the television to transport us to distant lands and virtual worlds to be our new state of existence. Today, VR in the form of head-mounted displays is one of the pinnacle technologies believed to afford such immersion. VR had originally been expensive, complicated and hence outside the reach of the average consumer [43]. As technological advancements unfolded, VR became more accessible through relatively cheaper and easier to use headmounted displays (headsets) [3, 5, 15] such as the Oculus Rift [53] and PlayStation VR [54]. Lead headset vendors, such as HTC, Facebook/Oculus, and Samsung continue to advertise price reductions to make VR accessible to an even broader audience [55]. With these developments, VR was positively placed on
Gartner's technology hype cycle [56], and it was expected that it would soon become an integral part of daily life $[5,14,19]$.

While research of and investment in VR continue $[3,5,43]$, as is also seen in announcements by Facebook to integrate VR in the online social experience [57], consumer adoption of VR is staggered behind compared to expectations and the sizes of these active investments in VR. Many individuals who acquire a VR headset seem reluctant to frequently use it on a daily basis as social media and informal blogs and reports indicate. Consequently, consumer spending on VR content and hardware upgrades is less than seen in closely connected media industries (television, gaming, mobile phones etc.), even while taking into account the comparative sizes of these industries. While profits and returns on investment are important in any industry, they are especially important in fastpaced, technological industries to ensure their sustainability. The current situation is of danger to VR industries and content providers and this relative lack of frequent VR use is a possible sign of consumer dissatisfaction with VR experiences, which presents growth opportunities for VR industries to understand and enhance current user experiences in VR.

While there are many avenues for investigating user experiences in VR such as looking into the discomfort induced by VR, known as VR sickness or cybersickness, which has been extensively researched $[1,44]$ or by researching enabling technologies and their utilization [5], the essence of VR is, arguably, telepresence: the feeling of being immersed in realities outside immediate ones $[15,25,43]$. It is hence of value, to understand the degree to which VR has been able to engulf users [25], namely to investigate the experience of being in flow in VR. Flow, by its nature of being a multi-dimensional experience, flow, encompasses concepts central to VR experiences such as of transportation and immersion [14, 49, 50], further strengthening the importance of its research.

Research on various types of information systems has positively connected experiences of flow and immersion with prolonged engagement with immersive 
systems [7, 24] and positive outcomes from their use $[41,51]$, it is very likely that experiencing flow in VR can similarly prolong VR use per session and overall, as well as improve outcomes from VR use such as entertainment or learning and consequently, positively impact consumer adoption and spending on VR. Little research, however, has looked into the degree and conditions under which users experience flow in VR, or its potential impact on VR use. The aim of this research is to investigate which preconditions of experiencing flow lead to flow in VR and how the experience of that flow impacts $V R$ use. We employ survey data $(n=681)$ of VR users (i.e. those who have used Head Mounted Display-based VR), analyzed through Structural Equation Modeling (SEM). The results provide insight into the possible catalysts of flow in VR and its behavioral outcomes. The research offers directions for how VR content can be better structured towards inducing flow, immersion, telepresence and hence lead to prolonged use of VR.

\section{Background and related work}

\subsection{Flow}

Flow denotes experiences where we are fully immersed in activities that capture our interests to the exclusion of most other realities outside of ourselves [12]. We for example play a game or read a book for a couple of minutes, only to find out that an hour has passed and that we have missed the sound of a buzzing phone next to us. Research has for decades been directed towards uncovering what flow is, how it emerges and what preconditions and outcomes there are to experiencing flow. Perhaps the most seminal line of research on flow has been led by Csikszentmihalyi and colleagues (e.g., [12, 13, 34]) where they identified nine constructs to describe the experience of flow. A plethora of research around the flow state employed this conceptualization to measure and characterize flow in various contexts $[10,21,29,49,52]$ and to specially understand how to design technologies, activities and services that induce flow $[16,35]$.

According to Csikszentmihalyi [12, 13]: flow is described as an autotelic experience that is intrinsically rewarding, meaning that flow-inducing activities become performed for the sake of themselves rather than for purposes outside of them [34, 52]. Flow is characterized with heightened concentration on the task at hand [35], as such, individuals hardly think of themselves or their personal states while in flow [7]. Individuals experience a transformation of time [7, 16] as experiential time replaces clock time; minutes, for example, last hours [12]. Finally, flow is characterized with a merging of action and awareness [34, 35]; where concentration is focused on the activity at hand that individuals are not aware of thoughts outside of it.

In terms of preconditions of flow: there needs to be a challenge-skill balance for flow to emerge [7, 10] which is about finding an optimal balance between an individual's skills and the demands of the activities they are engaged in $[12,34]$ as indicated by research in many contexts such as in the contexts of online shopping [35] or in gaming [7, 10]. Unchallenging activities may elicit boredom [16] while extreme challenge may elicit anxiety [7].

While life is generally characterized with ambiguity and uncertainty, as to what is it that individuals are supposed to do next, flow-inducing activities are characterized with clear goals that exactly communicate to individuals what it is that they are supposed to do, allowing their attention to be undivided [12] and improving the outcomes from the engagement with the activity [16]. Next to clear goals, unambiguous feedback allows individuals to maintain or correct their behavior in line with the goals that they are trying to attain from an activity, facilitating flow [12]. Games and sports are considered to be apt environments for experiencing flow as they tend to provide both; clear goals and unambiguous feedback [34]. For example; games tend to indicate to gamers that they have succeeded or failed in a mission as well as what levels and expertise they have gained from their play, hence contributing to the creation of positive experiences of immersion and flow while playing [10].

A sense of control is necessary for flow and denotes feelings of confidence that one can deal with the task at hand $[16,34,20]$ such as browse a website, use a new device or solve a math problem. This way, the sense of control may be theoretically similar to self-efficacy: a person's belief in their abilities [20]. Sense of control often manifests in a command of the lingo of the flow-inducing activities, the physical movements needed to engage with it as well as the cognitive skills needed to perform the activity [10]. The more users feel a sense of control, the more they tend to experience flow [35]. Nonetheless, activities that individuals are perfectly in control of, with little challenge may negatively impact feelings of flow [16].

Since flow is an optimal psychological experience that individuals enjoy [34], it is not surprising that the more individuals experience flow, the more they engage, or at least wish to engage, with the flowinducing activity $[12,16,34,51]$. Flow is positively associated with commitment to and repeated engagement with activities [16, 34] and especially repetitive use of technologies [51]. Experiencing and seeking flow is similarly perhaps why individuals engage with autotelic activities at large such as playing games or sports [10]. In terms of outcomes from 
experiencing flow and this increased engagement with flow-inducing activities: flow positively impacts productivity at large $[35,51]$ and facilitates the attainment of many desirable outcomes in life [12, 34, 52]. For example; students who experience flow seem to learn better and enjoy learning more than others $[16$, $23,40]$. Individuals are more loyal to online retailers where they experience flow [7]. Being in flow encourages individuals to spend more time on the flow-inducing activities, such as visiting more pages of a website or seeking more information online [35, 51], or in chat rooms to teach second languages [16].

\subsection{Flow in VR}

"Virtual Reality" (VR) has historically referred to a number of technologies such as the internet, online worlds, games, and many other such digital technologies [19, 20, 25]. However, today the term "Virtual Reality" primarily refers to visual output technologies that aim to cover a user's field of view, such as through head mounted displays [15, 43] or CAVE systems [11]. More specifically, VR, today, denotes the use of stereoscopic $3 \mathrm{D}$ visual output technology that aims to produce the psychological experience of 'being there', i.e. experiencing content as a 3-dimensional, immersive space [3] (although viewing $2 \mathrm{D}$ content through the same techniques is possible). VR has shown merits in various fields: entertainment [29], controlled research [15], therapy [45] and building human connection [5, 27].

While wearing a headset to experience VR, most of a user's senses (e.g. sight, hearing) are purposefully directed to a singular context [50], which may facilitate a higher concentration on task and provide grounds for autotelic experiences and immersion. VR, hence, appears to be a likely environment for flow to emerge $[49,50]$. The experience of being in flow in VR is thought to be a manifestation of efficient telepresence and immersion from these technologies [14, 49, 50]. The more VR became accessible to the average consumer, the more the hype around it and expectations of flow and immersion out of it grew [3].

Experimental research compared the extent to which individuals experience flow and immersion while viewing media content in VR versus 2D monitors, highlighting that users experience flow [29] and immersion [42] more in VR, increasing their satisfaction with some of the consumed media content. Experimental research also indicated that being in VR may foster deeper immersive experiences that improve creative work [50]. While such findings may paint a positive picture of flow in VR, there is a dearth in our understanding of flow in VR. For example: work carried out to compare experiences of flow across different VR content types and use lengths did not reach a clear conclusion on the extent to which individuals lose their sense of time and experience flow in VR [49]. Another experimental research failed to identify a significant correlation between different VR technologies and experiences of flow, specifically pointing towards a need for revisiting the flow theory in the context of VR so as to identify whether it holds in this new context [32]. Furthermore, most of the studies on flow in VR have been in experimental settings that may not reflect real experiences.

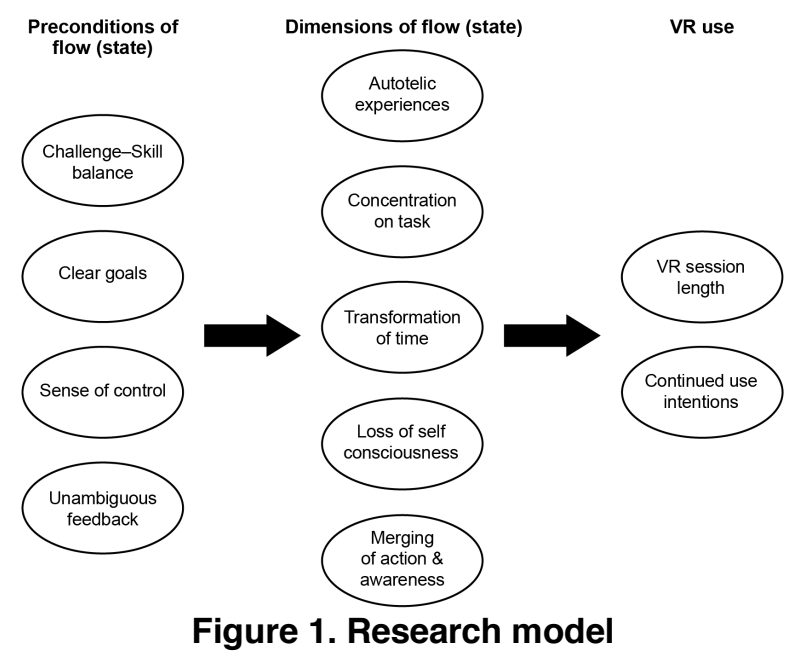

As there is currently a dearth of literature and findings on experiences of flow in VR, we investigated all the possible associations between preconditions of flow (challenge-skill balance, clear goals, sense of control, and unambiguous feedback) and all individual characteristics of flow (autotelicy, concentration on task, transformation of time, loss of self- consciousness and merging of action and awareness) to develop a holistic understanding of flow in VR. Furthermore, we investigated how each of these flow characteristics associate with VR session length and intentions to continue VR use in the future. The research model investigated is presented in Figure 1.

\section{Methods and data}

\subsection{Participants}

An online survey was employed to gather data $(\mathrm{n}=$ 681) from individuals who have previously used VR. Table 1 presents the demographics of the participants. The participants were predominantly male (74.6\%). The mean age was 32.76 years. Most were employed full-time $(73.3 \%)$ and had a bachelor's degree (49.2\%). One-fourth $(25 \%)$ did not spend any money on VR 
content overall, while an almost equal-sized group (27.6\%) spent between 1 to 99 USD. Regarding VR hardware, $19.5 \%$ reported no spending on it, $15.0 \%$ reported spending between 1 to 99 USD, and 18.4\% reported spending between 400 to 599 USD. The data analyzed was only of the respondents who passed attention checks and who fully completed the survey.

\subsection{Measurements}

Since flow is a latent psychological experience [7, $12,52]$, a survey was employed in this study as surveys can be considered an appropriate method to measure individuals' experiences of reality [4, 18, 36, 37]. Flow was measured using the Dispositional Flow Scale (DFS-2) developed by Jackson et al. [28], containing 36 items measuring individuals' tendency to experience flow in terms of the nine flow constructs identified by Csikszentmihalyi [13] as previously defined and discussed in the background section of this manuscript. The items were measured through fivepoint likert scales through which respondents were asked to evaluate the likelihood of them having experienced flow when they had previously used VR. The Dispositional Flow Scale (DFS-2) has previously been employed by several research investigating flow, e.g., [21, 52] in technological contexts. A leading prefix "When, using VR..." was added to the Flow Scale (DFS-2) items to make sure they are contextualized. VR session length was measured through an item asking participants to estimate the average time they spend in VR "How long is your average virtual reality use session? Answer in minutes.". Intentions to continue the use of VR in the future were adapted from [48].

\subsection{Validity and reliability}

Structural Equation Modeling (SEM) was used to evaluate the research model. The sample of this study was sufficient to meet requirements for PLS-SEM according to several criteria, as it is ten times greater than the number of inner model construct paths [2, 8], and each construct is mirrored with more than five participants [6]. Since this research is oriented towards predicting user experiences (of flow) and future behavior (intentions to continue VR use) rather than estimating model fit, we employed component-based PLS-SEM through SmartPLS over covariance SEM [2, 9]. Furthermore, PLS-SEM does not require restrictive assumption as to the parametric nature of the data [38].

Convergent validity and reliability requirements were evaluated through three measures: Average Variance Extracted (AVE), Composite Reliability (CR), and Cronbach's Alpha (Alpha) as presented in
Table 2. As per recommended thresholds [17], all AVE values are greater than 0.5 , all $\mathrm{CR}$ values are greater than 0.7. Cronbach's alphas either exceeds 0.7 or is on the threshold of that. There was no missing data.

The square root of the AVE value of any variable (the bolded diagonal line in Table 2) is larger than the correlations between that variable and the rest of the variables in the model and all intercorrelations between the variables were less than 0.9 [8, 17], indicating discriminant validity requirements are met. Furthermore, all items only loaded most on the variables they measure, with a loading of 0.7 or higher. 1 item had a loading of 0.557 and two had loadings of 0.600 and 0.695 each. Considering the sample size of the study $(n=681)$ and the thresholds outlined by Hair et al. [58], the data meats loading threshold. Furthermore, multicollinearity was not detected between the items as all VIF values are below 5 [58].

\section{Results}

As indicated in Figure 2, the investigated preconditions of flow account for $45.8 \%$ of the variance in autotelic experiences, $55.4 \%$ of the variance in concentration on task, $5.7 \%$ of the variance in transformation of time, $20.6 \%$ of the variance in loss of self-consciousness and $30.5 \%$ of the variance in the merging of action and awareness. These flow characteristics, collectively, accounted for $9.7 \%$ of the variance in VR session lengths and $47.4 \%$ of the variance in intentions to continue VR use of in the future. The complete obtained results are in Table 3, where the significant results are highlighted in bold. As the $\mathrm{Q}^{2}$ values in Table 3 indicate, all significant relationships in the data have $\mathrm{Q}^{2}$ above 0 (except for 2 relationships), indicating that they are of predictive power [59].

\section{Discussion}

\subsection{Theoretical implications}

The first overall observation from the obtained findings seems to indicate that the flow preconditions and outcomes from general flow theory, seem to hold in VR. In terms of preconditions: challenge-skill balance appears has a significant association with all experiences of flow in VR. Challenge-skill balance is indeed central in experiences of flow in various settings outside of VR [7, 10, 12, 34, 35]. However, it is important to highlight that while creating a cognitively challenging environment may induce flow, VR use in itself often incurs challenges with regards to its set-up and perhaps the relative discomfort associated with being in VR. Challenge in 
Table 1: Demographics of study participants

\begin{tabular}{|c|c|c|c|c|c|c|c|}
\hline & & \# & $\%$ & & & \# & $\%$ \\
\hline $\begin{array}{l}\text { Age } \\
(\mathrm{SD}=9.69) \\
(\text { Mean }=32.76) \\
(\text { Median }=31.00)\end{array}$ & $\begin{array}{l}-20 \\
20-29 \\
30-39 \\
40-49 \\
50-59 \\
60-\end{array}$ & $\begin{array}{l}33 \\
259 \\
251 \\
97 \\
30 \\
11\end{array}$ & $\begin{array}{l}4.8 \\
38.0 \\
36.9 \\
14.2 \\
4.4 \\
1.6\end{array}$ & Employment & $\begin{array}{l}\text { Full-time } \\
\text { Part-time } \\
\text { Student } \\
\text { Unemployed } \\
\text { Retired } \\
\text { Other }\end{array}$ & $\begin{array}{l}499 \\
57 \\
65 \\
31 \\
8 \\
21\end{array}$ & $\begin{array}{l}73.3 \\
8.4 \\
9.5 \\
4.6 \\
1.2 \\
3.1\end{array}$ \\
\hline \multirow[t]{2}{*}{ Spending on VR content } & \multirow{2}{*}{$\begin{array}{l}\$ 0 \\
\$ 1 \text { to } \$ 99 \\
\$ 100 \text { to } \$ 199 \\
\$ 200 \text { to } \$ 399 \\
\$ 400 \text { to } \$ 599 \\
\$ 600 \text { or more }\end{array}$} & \multirow{2}{*}{$\begin{array}{l}170 \\
188 \\
107 \\
118 \\
41 \\
57\end{array}$} & \multirow{2}{*}{$\begin{array}{l}25.0 \\
27.6 \\
15.7 \\
17.3 \\
6.0 \\
8.4\end{array}$} & Gender & $\begin{array}{l}\text { Male } \\
\text { Female } \\
\text { Other }\end{array}$ & $\begin{array}{l}508 \\
163 \\
10\end{array}$ & $\begin{array}{l}74.6 \\
23.9 \\
1.5\end{array}$ \\
\hline & & & & \multirow[t]{2}{*}{ Annual income } & $\begin{array}{l}\text { Less than } \$ 19,999 \\
\$ 20,000 \text { to } \$ 39,999\end{array}$ & $\begin{array}{l}251 \\
143\end{array}$ & $\begin{array}{l}36.9 \\
21.0\end{array}$ \\
\hline \multirow[t]{2}{*}{$\begin{array}{l}\text { Spending } \\
\text { hardware }\end{array}$} & \multirow{2}{*}{$\begin{array}{l}\$ 0 \\
\$ 1 \text { to } \$ 99 \\
\$ 100 \text { to } \$ 199 \\
\$ 200 \text { to } \$ 399 \\
\$ 400 \text { to } \$ 599 \\
\$ 600 \text { to } \$ 799 \\
\$ 800 \text { to } \$ 999 \\
\$ 1000 \text { or more }\end{array}$} & \multirow{2}{*}{$\begin{array}{l}133 \\
102 \\
65 \\
87 \\
125 \\
34 \\
35 \\
100\end{array}$} & \multirow{2}{*}{$\begin{array}{l}19.5 \\
15.0 \\
9.5 \\
12.8 \\
18.4 \\
5.0 \\
5.1 \\
14.7\end{array}$} & & $\begin{array}{l}\$ 60,000 \text { to } \$ 79,999 \\
\$ 80,000 \text { to } \$ 99,999 \\
\$ 100,000-119,999 \\
\$ 120,000-\$ 139,999 \\
\$ 140,000 \text { or more } \\
\text { Refused to disclose }\end{array}$ & $\begin{array}{l}118 \\
76 \\
37 \\
19 \\
6 \\
26 \\
5\end{array}$ & $\begin{array}{l}11.2 \\
11.2 \\
5.4 \\
2.8 \\
0.9 \\
3.8 \\
0.7\end{array}$ \\
\hline & & & & Education & $\begin{array}{l}\text { High school } \\
\text { Bachelor's degree } \\
\text { Master's degree } \\
\text { Doctoral degree } \\
\text { Other }\end{array}$ & $\begin{array}{l}148 \\
335 \\
129 \\
16 \\
53\end{array}$ & $\begin{array}{l}21.7 \\
49.2 \\
18.9 \\
2.3 \\
7.9\end{array}$ \\
\hline
\end{tabular}

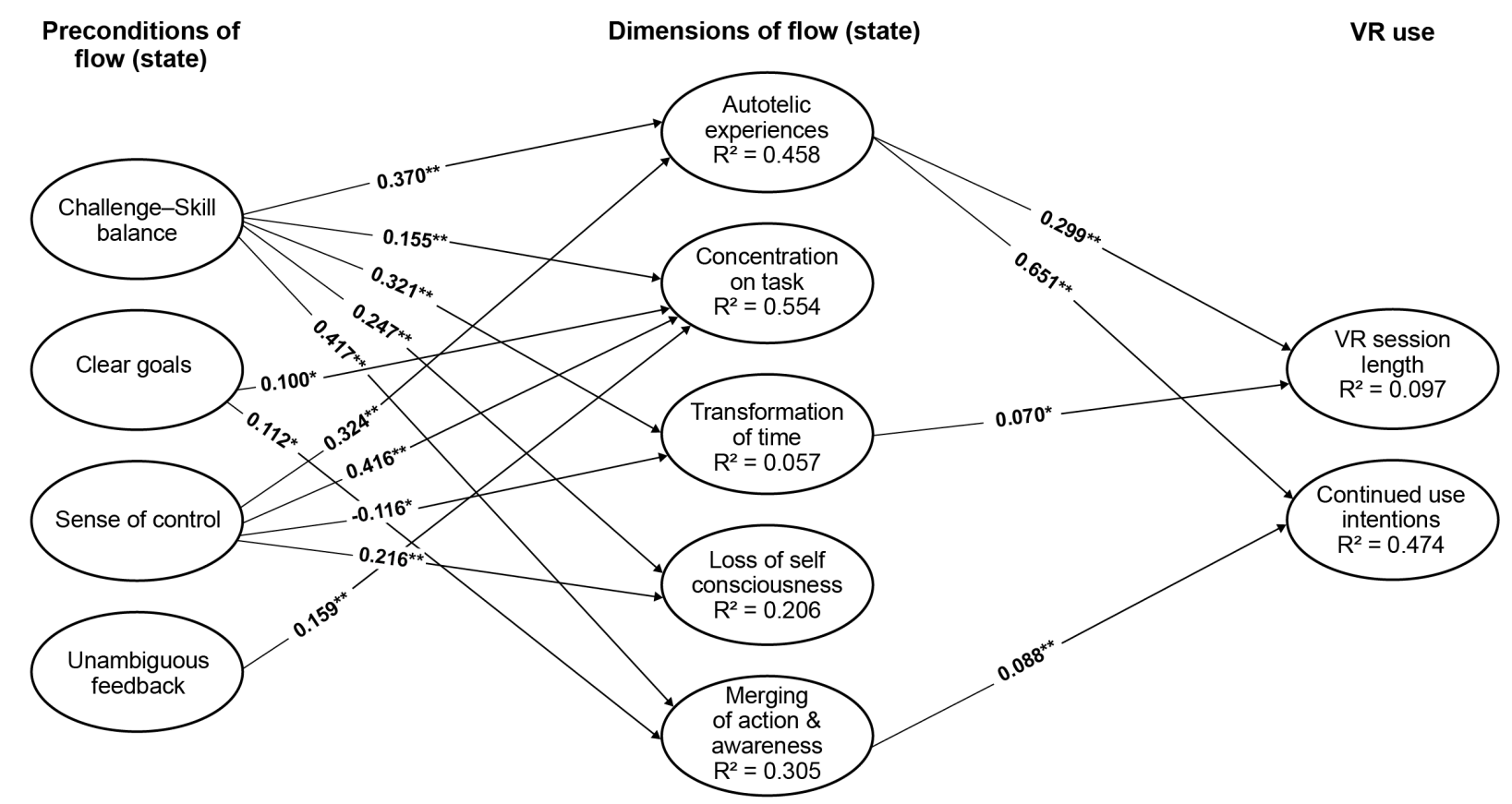

Figure 2: Results: ${ }^{*}=p<0.1,{ }^{* \star}=p<0.05$. (Non-significant paths omitted for clarity. See Table 3 for all path coefficients) 
Table 2: Convergent and discriminant validity

\begin{tabular}{|lcccccccccccccc|}
\hline & $\alpha$ & CR & AVE & AE & CG & CSB & CT & MAA & LSC & SC & SL & TT & UF & CU \\
AE & 0.847 & 0.897 & 0.685 & $\mathbf{0 . 8 2 8}$ & & & & & & & & & & \\
CG & 0.827 & 0.885 & 0.658 & 0.507 & $\mathbf{0 . 8 1 1}$ & & & & & & & & & \\
CSB & 0.721 & 0.828 & 0.551 & 0.629 & 0.640 & $\mathbf{0 . 7 4 2}$ & & & & & & & & \\
CT & 0.748 & 0.841 & 0.571 & 0.568 & 0.619 & 0.617 & $\mathbf{0 . 7 5 6}$ & & & & & & & \\
MAA & 0.695 & 0.814 & 0.525 & 0.458 & 0.432 & 0.539 & 0.436 & $\mathbf{0 . 7 2 4}$ & & & & & & \\
LSC & 0.854 & 0.902 & 0.696 & 0.341 & 0.343 & 0.421 & 0.403 & 0.378 & $\mathbf{0 . 8 3 4}$ & & & & & \\
SC & 0.852 & 0.900 & 0.693 & 0.617 & 0.716 & 0.698 & 0.709 & 0.438 & 0.413 & $\mathbf{0 . 8 3 3}$ & & & & \\
SL & 1.000 & 1.000 & 1.000 & 0.297 & 0.106 & 0.146 & 0.125 & 0.147 & 0.117 & 0.171 & $\mathbf{1 . 0 0 0}$ & & & \\
TT & 0.872 & 0.912 & 0.723 & 0.373 & 0.101 & 0.220 & 0.179 & 0.345 & 0.144 & 0.087 & 0.175 & $\mathbf{0 . 8 5 0}$ & & \\
UF & 0.824 & 0.883 & 0.654 & 0.531 & 0.769 & 0.680 & 0.638 & 0.427 & 0.354 & 0.715 & 0.130 & 0.106 & $\mathbf{0 . 8 0 9}$ & \\
CU & 0.875 & 0.916 & 0.733 & 0.682 & 0.402 & 0.461 & 0.376 & 0.384 & 0.276 & 0.431 & 0.382 & 0.285 & 0.407 & $\mathbf{0 . 8 5 6}$ \\
\hline
\end{tabular}

Table 3: Full results

\begin{tabular}{|c|c|c|c|c|c|c|}
\hline \multirow{2}{*}{$\begin{array}{l}\text { Associations } \\
\text { Flow Preconditions }\end{array}$} & & \multirow[t]{2}{*}{$\beta$} & \multirow[t]{2}{*}{$\mathbf{P}$} & \multicolumn{2}{|c|}{ CI 95\% } & \multirow[t]{2}{*}{$\mathbf{Q}^{2}$} \\
\hline & Flow experiences & & & & & \\
\hline \multirow[t]{5}{*}{ Challenge-Skill balance -> } & Autotelic Experiences & $0.370 * *$ & 0.000 & 0.270 & 0.473 & 0,0522 \\
\hline & Concentration on Task & $0.155^{* *}$ & 0.000 & 0.081 & 0.236 & 0,0071 \\
\hline & Transformation of Time & $0.321 * *$ & 0.000 & 0.201 & 0.451 & 0,0311 \\
\hline & Loss of Self Consciousness & $0.247 * *$ & 0.000 & 0.147 & 0.361 & 0.0000 \\
\hline & Merging of Action and Awareness & $0.417 * *$ & 0.000 & 0.323 & 0.515 & 0,0445 \\
\hline \multirow[t]{5}{*}{ Clear Goals -> } & Autotelic Experiences & 0.004 & 0.939 & -0.103 & 0.100 & $-0,0014$ \\
\hline & Concentration on Task & $0.100 *$ & 0.057 & 0.001 & 0.198 & 0,0014 \\
\hline & Transformation of Time & 0.002 & 0.971 & -0.127 & 0.135 & 0.0000 \\
\hline & Loss of Self Consciousness & 0.014 & 0.829 & -0.119 & 0.143 & $-0,0213$ \\
\hline & Merging of Action and Awareness & $0.112 *$ & 0.051 & 0.001 & 0.225 & 0,0012 \\
\hline \multirow[t]{5}{*}{ Sense of Control -> } & Autotelic Experiences & $0.324 * *$ & 0.000 & 0.217 & 0.424 & 0,0338 \\
\hline & Concentration on Task & $0.416^{* *}$ & 0.000 & 0.333 & 0.507 & 0,0454 \\
\hline & Transformation of Time & $-0.116^{*}$ & 0.075 & -0.242 & 0.016 & 0,0031 \\
\hline & Loss of Self Consciousness & $0.216^{* *}$ & 0.000 & 0.098 & 0.331 & $-0,0071$ \\
\hline & Merging of Action and Awareness & 0.053 & 0.368 & -0.062 & 0.162 & 0.0000 \\
\hline \multirow[t]{5}{*}{ Unambiguous Feedback -> } & Autotelic Experiences & 0.044 & 0.432 & -0.072 & 0.152 & 0.0000 \\
\hline & Concentration on Task & $0.159 * *$ & 0.004 & 0.053 & 0.263 & 0,0056 \\
\hline & Transformation of Time & -0.031 & 0.667 & -0.182 & 0.104 & 0.0000 \\
\hline & Loss of Self Consciousness & 0.021 & 0.745 & -0.103 & 0.144 & $-0,0201$ \\
\hline & Merging of Action and Awareness & 0.019 & 0.755 & -0.106 & 0.133 & $-0,0012$ \\
\hline Flow experiences & Flow outcomes & & & & & \\
\hline \multirow[t]{2}{*}{ Autotelic Experiences -> } & VR session length & $0.299 * *$ & 0.000 & 0.220 & 0.378 & 0,0545 \\
\hline & Continued use intentions & $0.651 * *$ & 0.000 & 0.572 & 0.722 & 0,2474 \\
\hline \multirow[t]{2}{*}{ Concentration on Task -> } & VR session length & -0.073 & 0.109 & -0.161 & 0.018 & 0,0011 \\
\hline & Continued use intentions & -0.050 & 0.222 & -0.129 & 0.028 & 0,0015 \\
\hline \multirow[t]{2}{*}{ Transformation of Time -> } & VR session length & $0.070 *$ & 0.082 & -0.010 & 0.148 & 0,0011 \\
\hline & Continued use intentions & 0.015 & 0.647 & -0.042 & 0.087 & 0.0000 \\
\hline \multirow[t]{2}{*}{ Loss of Self Consciousness -> } & VR session length & 0.032 & 0.393 & -0.037 & 0.109 & $-0,0033$ \\
\hline & Continued use intentions & 0.038 & 0.267 & -0.035 & 0.101 & 0,00148 \\
\hline Merging of Action and & VR session length & 0.006 & 0.877 & -0.074 & 0.087 & $-0,0044$ \\
\hline Awareness -> & Continued use intentions & $0.088 * *$ & 0.007 & 0.028 & 0.154 & 0,00444 \\
\hline
\end{tabular}


VR needs to be created in the right places to capture rather than deter the audience from VR use. One of the longest-standing notions in technology and systems adoption research is the necessity for a system or technology to be easy to use for it to be adopted [46, 47, 48]. Similarly, as with most media, if the media content is too challenging (or not challenging enough), individuals may not persist in consuming it but may rather move to another form of media. Balancing ease of use and challenge in VR is perhaps multi-layered between physical and content challenges and worthy of further study to understand how to balance it

Clear goals have positive associations with concentration on task and merging of action and awareness in VR. Clear goals direct individuals as to what it is that they should do next $[12,16,35]$. This clear direction of attention can allow for merging of action and awareness, where individuals become unaware of anything other than the activity at hand [34, 35] as our results indicate. Even in exploratory activities in VR [14], there is still a clear goal in place (to explore), even if it may be relatively less defined, allowing still for experiences of flow to emerge such as is seen in online browsing of shops [35].

Sense of control is positively associated with all flow experiences. This is perhaps intuitive as it is unlikely that feeling a complete loss of control would lead to positive experiences but rather discomfort and disorientation. Such negative experiences are unlikely to facilitate flow. VR users report positive perceptions of their sense of in control in VR even over non-VR mediums [14, 42] as VR allows exploration that may not be possible otherwise (e.g., touching artefacts in virtual museums), which perhaps provide a sense of control different than what may be experienced in physical environments, contributing to flow.

Unambiguous feedback positively associated with concentration on task. As feedback intervention theory indicates: clear and specific feedback is essential to direct human behavior towards activities they are or wish to be engaged with [30, 31]. Unambiguous feedback may not necessarily be in relation to certain goals that users are trying to achieve from the use of VR, but such feedback can direct users towards further exploration of the virtual worlds and further actions they can do in it allowing them to be immersed in the virtual world and concentrate on the task at hand as our results indicate. Unambiguous feedback in VR can come in different forms such as in forms of visual cues, sound chimes and such responses produced by a system as users interact with it that perhaps should be consistent and aligned with user expectations of the world they are in so that they are unambiguous.

Experiences of flow in VR are associated with intentions to continue VR use and with longer VR sessions, although the association with the latter is perhaps of lesser strength. Autotelic experience in VR is a prominent characteristic of flow that positively associates with both VR use session length and intentions to continue VR use. As indicated by the larger stream of research on hedonic systems [26, 33, 39] and closely connected as gamified systems which aim to increase utility through autotelicy [21, 22, 24], hedonic experiences tend to positively associate with lengthy use of systems per session and continuously. Recent extensions of TAM reflect these findings and include affective aspects as important dimensions in technology acceptance and continued use [46, 47, 48]. In the VR context, research indicates that individuals who have had positive experiences in VR, intend to use VR again in the future [14]. Merging of action and awareness similarly associated with intentions to continue the use of VR. Perhaps the more individuals start to experience a degree of automatic, unconscious engagement with VR and the more their awareness of the mechanics of such engagement disappears, the more they will intend to use VR as perhaps the use of VR will appear less challenging but rather enjoyable.

Transformation of time positively associated with VR sessions length. This is perhaps intuitive as the more individuals discount the time they spend on an activity, the more likely they are to continue to engage with it as they would think that they have not spent a long time on it yet. Notably, previous research on flow in VR [49] have not uncovered what could be a precondition for transformation of time in VR. Our findings indicate that challenge-skill balance positively associates with transformation of time, indicating that VR content of suitable challenge to the users may distort their sense of time and lead to longer use of VR. However, unexpectedly, sense of control is negatively associated with transformation of time in VR. This is an unexpected finding as being in command of one's activity strengthens transformation of time as previous research indicates $[16,34,20]$. Perhaps the association is somehow connected to user expectation of VR in terms of expecting to be in new dimensions of reality, where, perhaps their sense of activity should be different. We have no immediate explanation for this finding. It however confirms that flow may be experienced differently in VR, necessitating contextualized study of VR in flow.

No significant associations were uncovered between concentration on task and intentions to continue VR use or lengthier VR sessions. It is possible that what individuals appreciate most about VR is that it can afford exploratory activities [14], which may not necessarily require "concentration on task" in the traditional sense. What is, however, most surprising is the lack of associations between loss of 
self-consciousness and intentions to continue VR use or lengthier VR sessions. Research on flow has long attributed continued and lengthy engagement with activities to several factors including loss of selfconsciousness [12, 13, 34]. Perhaps the loss of selfconsciousness in VR is uncomfortable as it is accompanied with a separation from reality and a loss of sense of the immediate environment that it creates dissociative rather than positively experiences that individuals would not wish to pursue in VR in specific. These unexpected findings require further investigation as they support the notion that there may be a need for revising flow theories in the emerging VR context [32].

\subsection{Practical implications}

Flow researchers have often discussed interventions aimed at inducing flow [34]. Such interventions often take form in restructuring activities and environments towards ones that allow for the emergence of flow. Other interventions have focused on individuals and stimulating a need for pursuit of autotelicy in them that may encourage them to pursue flow. While the VR industry perhaps cannot directly influence individuals and their (autotelic) personalities and tendencies (although marketing campaigns and sales strategies may be worthy of investigation for these purposes), it can influence the content available to consumers. This provides both an opportunity and a challenge to VR hardware and software designers. Autotelicy and flow are subjective and may not be the easiest experiences to induce intentionally through design.

The use of VR technologies in specific, is not yet seamless and involves a plethora of physical inconveniences such as discomfort from headsets, needed setup space, dizziness, and fatigue amongst other inconveniences [1,44]. VR content similarly is still not at the heights of visual sharpness and may evoke feeling of artificiality [5]. These factors amongst others complicate VR experiences and may hinder experiences of flow in VR as the user remains vividly reminded with their immediate physical experience and the artificiality of VR. However, the more we understand the preconditions of flow in VR, the better VR hardware and software can be designed to induce flow and immersive experiences that lead to lengthy, enjoyable and continued VR use [14], possibly leading to increased consumer spending on VR.

Our results show that autotelic experiences of flow seem to be mainly associated with challenge-skill balance and sense of control, perhaps indicating the importance of these two factors in facilitating autotelic experiences in VR and consequently longer VR use and possibly increased spending. Striking a balance between content consumption ease and challenge in consumption is perhaps hard in VR where users are often faced with struggles preceding and outside of those placed by the content itself that is being consumed. Such challenges pertain to for example, VR setup, suspension of disbelief in VR and movement in VR. Seated consumption of VR may eliminate some challenges such as pertaining to available space and movement, nonetheless, being next faced with content that is too cognitively demanding or uncomfortable may discourage users from continued VR use. Perhaps in line with these speculations is that merging of action and awareness positively associates with intentions to continue the use of VR. The more the use of VR feels natural and seamless, the more users may be ready to continuously use it and not feel discouraged to do so.

\subsection{Limitations and future research avenues}

While surveys are an optimal research method for reflecting the respondents' version of reality $[4,18,36$, $37]$ ), they involve self-reports that may be subject to miscommunication. The participants are self-selected which might exclude the voice of some user segments. Flow experience may vary by content, or headset type or other factors. While a generalized understanding is needed at this emerging stage of VR adoption research, research is encouraged to conduct comparative laboratory measurements of flow, collected immediately after participants engage with different VR content and headsets so as to contrast their experiences. Surveys where participants also reflect on their experiences with specific VR content types or headsets are similarly encouraged

Early research into VR adoption seems to indicate that a host of factors, next to experiences of immersion, influence adoption of VR [14]. It is thus of importance to continue the exploration of what factors influence continued use of VR use and what experiences next to flow may have a stronger contribution to lengthy and continued VR use. Research is encouraged to investigate VR adoption possibly through a uses and gratifications approach to uncover what is it that users are after from VR and whether the experiences VR provides fulfils these needs. Nuances in experiences of flow are also important $[14,16]$ and can be captured through observational, field or similar qualitative techniques. Research is encouraged to capture nuanced experiences of flow in real settings.

Flow is a subjective experience. It is influenced by various characteristics such as personality, the environments individuals are in (virtually and physically), age, mood, or gender [34] amongst other individualistic characteristics. While the scope of this work would not have been manageable with an exploration of all of these variables, future research is 
encouraged to augment our findings through a study of the effects of personal characteristics on experiences of flow in VR. Perhaps VR setups where physical space is available to individuals and where they use higher end headsets lead to better experiences of flow and more intentions to continue the use of VR.

\section{Acknowledgments}

This work was supported by the Finnish Foundation for Economic Education (grants: 12-6385 and 14-7824), the Centre of Excellence on Game Culture Studies (GameCult), and Marcus Mallenbergin tutkimussäätiö Satakunnan.

\section{References}

[1] S.L. Ames, J.S. Wolffsohn, and N.A. Mcbrien, "The development of a symptom questionnaire for assessing virtual reality viewing using a head-mounted display", Optometry and Vision Science 82(3), 2005, pp. 168-176.

[2] J.C. Anderson, and D.W. Gerbing, "Structural Equation Modeling in Practices: A review and recommended two-step approach", Psychological Bulletin 103(3), 1988, pp.411-423.

[3] C. Anthes, R.J. García-Hernández, M. Wiedemann, and D. Kranzlmüller, "State of the art of virtual reality technology", In proceedings of the 2016 IEEE Aerospace Conference, IEEE, 2016, pp. 1-19.

[4] C. Barker, and N. Pistrang, "Research Methods in Clinical Psychology: An introduction for Students and Practitioners", John Wiley \& Sons, 2012.

[5] E. Bastug, M. Bennis, M. Médard, and M. Debbah, "Toward interconnected virtual reality: Opportunities, challenges, and enablers", IEEE Communications Magazine 55(6), 2017, pp. 110-117.

[6] P.M. Bentler, and C.P. Chou, "Practical issues in structural modeling", Sociological Methods \& Research 16(1), 1987, pp. 78-117.

[7] J. Chen, "Flow in games (and everything else)", Communications of the ACM 50(4), 2007, pp. 31-34.

[8] W.W. Chin, "The partial least squares approach for structural equation modelling”, In G. A. Marcoulides (Ed.), Modern methods for business research, Lawrence Erlbaum Associates, London, 1998, pp. 295-336.

[9] W.W. Chin, B.L. Marcolin, and P.R. Newsted, "A Partial Least Squares Latent Variable Modeling Approach for Measuring Interaction Effects: Results from a Monte Carlo Simulation Study and an Electronic-Mail Emotion/Adoption Study", Information Systems Research 14(2), 2003, pp. 189 217.

[10] B. Cowley, D. Charles, M. Black, and R. Hickey, "Toward an understanding of flow in video games", ACM Computers in Entertainment 6(2), 2008.

[11] C. Cruz-Neira, D.J. Sandin, T.A. DeFanti, R.V. Kenyon, and J.C. Hart, "The CAVE: audio visual experience automatic virtual environment", Communications of the ACM 35(6), 1992, 64-73.
[12] M. Csikszentmihalyi, "Toward a psychology of optimal experience", In Flow and the foundations of positive psychology, Springer, Dordrecht, 2014, pp. 209-226.

[13] M. Csikszentmihalyi, "Beyond boredom and anxiety", San Francisco: Jossey-Bass, 1975

[14] D. tom Dieck, M.C. tom Dieck, T. Jung, and N. Moorhouse, “Tourists' virtual reality adoption: an exploratory study from Lake District National Park", Leisure Studies 37(4), 2018, pp. 371-383.

[15] J. Diemer, G.W. Alpers, H.M. Peperkorn, Y. Shiban, and A. Mühlberger, A. "The impact of perception and presence on emotional reactions: a review of research in virtual reality", Frontiers in psychology 6, 2015.

[16] J. Egbert, "A Study of Flow Theory in the Foreign Language Classroom", Canadian Modern Language Review 60, 2004, pp. 549-586.

[17] C. Fornell, and D.F. Larcker, "Structural Equation Models with Unobservable Variables and Measurement Error: Algebra and Statistics", Journal of Marketing Research 18(3), 1981.

[18] F. Fransella, "Personality: Theory, Measurement and Research”, Vol. 719, Routledge Kegan \& Paul, 1981.

[19] L. Freina, and M. Ott, "A Literature Review on Immersive Virtual Reality in Education: State Of The Art and Perspectives", eLearning \& Software for Education (1), 2015.

[20] T. Grodal, "Video games and the pleasure of control. In D. Zillmann \& P. Vorderer (Eds.), Media entertainment: The psychology of its appeal", Mahwah, NJ: Erlbaum, 2000, pp. 197-213

[21] J. Hamari, and J. Koivisto, "Measuring flow in gamification: Dispositional flow scale-2", Computers in Human Behavior 40, 2014, pp. 133-143.

[22] J. Hamari, and J. Koivisto, "Why do people use gamification services?", International Journal of Information Management 35(4), 2015, pp. 419-431.

[23] J. Hamari, D.J. Shernoff, E. Rowe, B. Coller, J. AsbellClarke, and T. Edwards, "Challenging games help students learn: An empirical study on engagement, flow and immersion in game-based learning", Computers in human behavior 54, 2016, pp. 170-179.

[24] L. Hassan, A. Dias, and J. Hamari, "How motivational feedback increases user's benefits and continued use: A study on gamification, quantified-self and social networking", International Journal of Information Management 46, 2019, pp. 151-162.

[25] C. Heeter C, "Being there: The subjective experience of presence", Presence: Teleoperators \& Virtual Environments 1(2), 1992, pp. 262-271.

[26] V.D Heijden, "User Acceptance of Hedonic Information Systems", MIS Quarterly 28(4), 2004, pp. 695-704.

[27] F. Herrera, J. Bailenson, E. Weisz, E. Ogle, and J. Zaki, "Building long-term empathy: A large-scale comparison of traditional and virtual reality perspective-taking", PloS one 13(10), 2018

[28] S.A. Jackson, and R.C. Eklund, "Assessing Flow in Physical Activity: The Flow State Scale-2 and Dispositional Flow Scale-2", Journal of Sport and Exercise Psychology, 24(2), 2002, pp. 133-150.

[29] D. Kim, and Y.J. Ko, "The impact of virtual reality (VR) technology on sport spectators' flow experience and 
satisfaction", Computers in Human Behavior 93, 2019, pp. 346-356.

[30] A.N. Kluger, and A. DeNisi, "The effects of feedback interventions on performance: A historical review, a metaanalysis, and a preliminary feedback intervention theory", Psychological Bulletin 119(2), 1996.

[31] A.N. Kluger, and A. DeNisi, "Feedback interventions: Toward the understanding of a double-edged sword", Current Directions in Psychological Science 7(3), 1998, pp. 67-72.

[32] C. Kwon, "Verification of the possibility and effectiveness of experiential learning using HMD-based immersive VR technologies", Virtual Reality, 2018, pp. 1-18. [33] C.P. Lin, amd A. Bhattacherjee, "Extending technology usage models to interactive hedonic technologies: A theoretical model and empirical test", Information Systems Journal 20(2), 2010, 163-181.

[34] J. Nakamura, and M. Csikszentmihalyi, "The concept of flow", In Flow and the foundations of positive psychology, Springer, Dordrecht, 2014, pp. 239-263.

[35] T.P. Novak, AND d.l. Hoffman, and Y.F. Yung, "Measuring the customer experience in online environments: A structural modeling approach", Marketing science 19(1), 2000, pp. 22-42.

[36] J. Nunnally, "Psychometric methods", New York: McGraw-Hill, 1978.

[37] A. Pinsonneault, and K.L Kraemer, "Survey Research Methodology in Management Information Systems: An Assessment", Journal of Management Information Systems 10(2), 1993, pp. 75-105.

[38] C. Ringle, S. Wende, and A. Will, Smart-PLS Version 2.0 M3, University of Hamburg, 2005.

[39] P. Rosen, and P. Sherman, "Hedonic information systems: Acceptance of social networking websites", In Proceedings of the 12th American Conference on Information Systems, AMCIS2006, AIS Electronic Library, Acapulco, Mexico, 2006, pp. 1218-1223.

[40] D.J. Shernoff, M. Csikszentmihalyi, B. Schneider, E.S. and Shernoff, "Student engagement in high school classrooms from the perspective of flow theory", In Applications of flow in human development and education, Springer, Dordrecht, 2014, pp. 475-494.

[41] M. Sigala, "The application and impact of gamification funware on trip planning and experiences: the case of TripAdvisor's funware", Electronic Markets 25(3), 2015, pp. 189-209.

[42] S.C. Simon, and T. Greitemeyer, "The impact of immersion on the perception of pornography: A virtual reality study", Computers in Human Behavior 93, 2019, pp. 141-148.

[43] M. Slater, and M.V.Sanchez-Vives, "Enhancing our lives with immersive virtual reality", Frontiers in Robotics and AI 3, 2016.

[44] A. Somrak, I. Humar, M.S. Hossain, M. F. Alhamid, M.A. Hossain, and J. Guna, "Estimating VR Sickness and user experience using different HMD technologies: An evaluation study", Future Generation Computer System, 94, 2019, pp. 302-316.

[45] L.R. Valmaggia, L. Latif, M.J. Kempton, and M. RusCalafell, "Virtual reality in the psychological treatment for mental health problems: An systematic review of recent evidence", Psychiatry Research 236, 2016, pp. 189-195.

[46] V. Venkatesh, and H. Bala, "Technology acceptance model 3 and a research agenda on interventions". Decision Sciences, 39(2), 2008, pp. 273-315.

[47] V. Venkatesh, and F.D. Davis, "A theoretical extension of the technology acceptance model: Four longitudinal field studies”, Management Science 46(2), 2000, PP. 186-204.

[48] V. Venkatesh, J.Y. Thong, and X. Xu. "Consumer acceptance and use of information technology: extending the unified theory of acceptance and use of technology", MIS quarterly 36(1), 2012, pp.157-178.

[49] W.G. Volante, J. Cruit, J. Tice, W. Shugars, and P.A. Hancock, "Time Flies: Investigating Duration Judgments in Virtual Reality", Proceedings of the Human Factors and Ergonomics Society Annual Meeting 62(1), SAGE Publications, CA: Los Angeles, 2018, pp. 1777-1781.

[50] X. Yang, P.Y. Cheng, L. Lin, Y.M. Huang, and Y. Ren, "Can an Integrated System of Electroencephalography and Virtual Reality Further the Understanding of Relationships Between Attention, Meditation, Flow State, and Creativity?" Journal of Educational Computing Research, 2018.

[51] J. Webster, L.K. Trevino, and L. Ryan, "The dimensionality and correlates of flow in human-computer interactions", Computers in Human Behavior 9(4), 1994, pp. 411-426.

[52] J.G. Whitmore, and W.T Borrie, "Exploring the usefulness of the dispositional flow scale for outdoor recreation activities", Proceedings of the 2005 Northeastern recreation research symposium, Bolton Landing, New York, USA, 2005, pp. 371-378.

[53] Oculus VR. 2017. "The best VR experience at the most affordable price: Rift bundle now $\$ 399$," retrieved February 23, 2019 from https://www.oculus.com/blog/the-best-vrexperience-at-the-most-affordable-price-rift-bundle-now$399 /$

[54] PlayStation. 2017. "PS VR bundles available at a greater value starting September 1," retrieved February 23, 2019 from https://blog.us.playstation.com/2017/08/28/ps-vrbundles-available-at-a-greater-value-starting-september-1/

[55] Vive. 2017. "New Vive price makes the best VR system more accessible to the mass market," retrieved February 23, 2019 from https://blog.vive.com/us/2017/08/21/htc-viveannounces-price-drop/

[56] Gartner. 2017. "Top trends in the Gartner hype cycle for emerging technologies, 2017," retrieved February 23, 2019 from https:/www.gartner.com/smarterwithgartner/toptrends-in-the-gartner-hype-cycle-for-emerging-technologies2017/

[57] Facebook. 2018. "Facebook developers' conference," $\begin{array}{llll}\text { retrieved } & \text { February } & 24, & 2019\end{array}$ https://developers.facebook.com/videos/f8-2018/f8-2018day-1-keynote/

[58] J. F. Hair, C. M., Ringle, and M. Sarstedt, "PLS-SEM: Indeed a Silver Bullet. The Journal of Marketing Theory and Practice." 19(2), 2011, pp.139-152

[59] S. Geisser, "A predictive approach to the random effect model”, Biometrika, 61(1), 1974, pp.101-107 